\title{
O papel do gestor e curador da informação nos novos comportamentos informacionais
}

Marina Romano Ale ixo ${ }^{I}$

http://orcid.org/0000-0002-7250-3374

Maria Jose Oliveira Fernandes ${ }^{I I}$

http://orcid.org/0000-0003-1654-4291

Gislane Costa ${ }^{I I I}$

http://orcid.org/0000-0003-4876-650X

\section{H. Soraia Ribeiro ${ }^{I V}$}

http://orcid.org/0000-0002-2892-9239

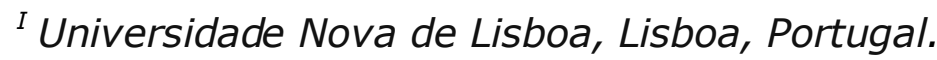

Mestranda de Gestão e Curadoria da Informação.

${ }^{\text {II }}$ Universidade Nova de Lisboa, Lisboa, Portugal.

Mestranda de Gestão e Curadoria da Informação.

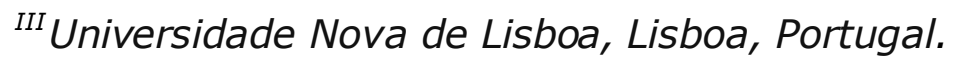

Mestranda de Gestão e Curadoria da Informação.

IV Universidade Nova de Lisboa, Lisboa, Portugal.

Mestranda de Gestão e Curadoria da Informação.

http://dx.doi.org/10.1590/1981-5344/3841

Com a nova tendência dos comportamentos informacionais, uma nova profissão emerge. O gestor e curador da informação traz uma transdisciplinaridade e 
multidisciplinaridade para mediar e colaborar com esse novo cenário. Este artigo objetiva a análise do papel do gestor e curador da informação face aos novos comportamentos informacionais, seu papel como mediador e colaborador e como seu trabalho vai ao encontro das novas políticas europeias de competências digitais. Por meio da revisão de literatura nas áreas de Ciência da Informação, da Tecnologia da Informação e da Sociologia desenvolveu-se uma análise crítica do tema abordado para difusão do perfil supracitado. Conclui-se a importância do gestor e curador da informação como mediador e colaborador na sociedade de informação.

Palavras-chave: Gestor e curador da informação; comportamento informacional; sociedade da informação; políticas públicas.

A new profession emerges with the information behaviour trend. The information manager and curator brings a multidisciplinar it and transdisciplinarity as a mediator and coworker in this scenario. The aim of this article is to analyse the information manager and curator's role and his/her relation with the new informational behaviour. Also, it is discussed his/her way as a mediator and as a coworker and his/her importance to work along with the public policies about digital competencies. A conceptual analysis of the subject of this study is developed through literature review in the fields of Information Science, Information Technology and Sociology. In conclusion, this study brings on the importance of the information manager and curator as a mediator and coworker in the information society.

Keywords: Information manager and curator; information behaviour; information society; public policies. 


\section{Introdu ção}

Com o crescimento exponencial da tecnologia, sobretudo da inteligência artificial, a sociedade poderá experienciar mudanças irreversíveis que a tornarão irreconhecível. Tal como ocorreu nas três revoluções científicas, a humanidade poderá passar por mais uma singularidade tecnológica, como postulou o matemático John VonNeumann (OLIVEIRA, 2018).

Tendo em vista que a sociedade tende à mudança, também as práticas informacionais são alteradas, dado que os novos comportamentos informacionais estão profundamente ligados ao meio ambiente e aos contextos sociais, políticos, econômicos e culturais. Consequentemente, as relações estabelecidas entre o usuário e a informação, quanto à aquisição, organização, interpretação e manipulação também se alteram.

A evolução contínua das tecnologias possibilita novos comportamentos, no entanto, pode-se afirmar que a busca de novos objetivos e as novas tendências humanas impulsionam a criação de novos paradigmas tecnológicos. O nomadismo digital, a coaprendizagem, o coempreendedorismo e o investimento em competências digitais são alguns exemplos que apontam a relação ambivalente do ser humano e da tecnologia.

Por conseguinte, este artigo tem como objetivo a análise do papel do gestor e curador da informação face aos novos comportamentos informacionais. Qual é o seu papel? É apenas um mediador ou é ele próprio um colaborador? Como seu trabalho vai ao encontro das novas políticas europeias de competências digitais?

Para a construção desse estudo, realizou-se uma revisão de literatura sobre temas transversais às áreas da Ciência da Informação, da Tecnologia da Informação e da Sociologia. Dessarte pôde-se convergir conceitos, assuntos e ideias de maneira a explanar e refletir sobre o papel do gestor e curador da informação e seus desafios face às novas tendências de comportamentos informacionais.

Este artigo traz três significativas contribuições: apresentação das novas tendências de comportamento informacional; a colaboração do gestor e curador da informação diante destas novas tendências; por último, a elucidação desta profissão emergente.

Para tal, estrutura-se de forma a apresentar a sociedade da informação, as competências digitais, as políticas públicas europeias, assim como o papel do gestor e curador da informação como mediador e colaborador dos novos comportamentos informacionais. 


\section{Sociedade da informação}

A tecnologia desde sempre transforma a maneira que o Homem se relaciona com seu próximo e com o meio em que vive. $O$ arado possibilitou o desenvolvimento da agricultura, permitindo que o Homem permanecesse por mais tempo em um mesmo local, logo, abandonando progressivamente o nomadismo. Séculos mais tarde, a revolução industrial transforma a relação do Homem com o tempo (tempo do mercador), com o dinheiro e com o trabalho, ao estabelecer horas, local fixo e salário determinado ao trabalhador.

Hoje, nota-se os efeitos do desenvolvimento tecnológico na sociedade da informação, uma vez que, ela nasceu da valorização e da troca da informação nas complexas redes de comunicação, como já antes abordado por autores como Castells (2002, 2003), Burke (2003), Gouveia (2004) e outros. Esta sociedade trouxe uma nova geração, os "nativos digitais"(SILVA, 2008) ou "geração Google" (LANZIet al., 2012), isto é, pessoas que nasceram na década de 1980 em diante, e as quais aprenderam a interagir com as tecnologias de informação e comunicação de forma contínua, de onde se originou o conceitolong life literacy(SILVA, 2008 , p. 32). Este conceito nada mais é do que aprendizagem ao longo da vida, ou seja, nada está adquirido, tudo está em constante mutação, seremos aprendizes toda a vida.

Seus hábitos informacionais revelam a ampla capacidade na utilização das tecnologias de informação e comunicação, no entanto, traz certa apreensão. A noção de que a internet é melhor "qualificada", por estar em constante atualização, a coloca em primeiro lugar como fonte de pesquisa. O volume de informações, comportamentos de pesquisa, a utilização das informações são temas que estão sendo abordados, como no estudo de Vitoriano e Gasque (2018), o que denota-se a preocupação com a qualidade e uso da informação pelos profissionais da informação, dado que isto pode apresentar sérios desafios para a consolidação do conhecimento dos futuros pesquisadores e edificadores da ciência e colaboradores em organizações.

Apesar da tecnologia proporcionar uma nova visão da realidade, ela também aponta para um certo retorno aos primórdios, onde a itinerância era a regra. Porém não mais por uma necessidade física (alimentação, água e clima), mas sim por um estilo de vida fora da "rotina regular, 'ganhando' liberdade do mundo corporativo"(NASH et al., 2018, p. 5).

O nomadismo digital, por exemplo, já é uma realidade graças ao avanço tecnológico que permite conciliar trabalho, aventura e viagens. Esta nova profissão que vem ganhando espaço e adeptos, depende da tecnologia para realizar suas tarefas de maneira remota, não estando dependente de uma base fixa para trabalhar. Essa questão pode estar na 
gênese de mais uma mudança profunda na relação do homem com o meio onde vive e com os seus hábitos informacionais. Além disso, essa nova tendência pode influenciar o investimento em tecnologias de informação e comunicação cada vez mais eficazes e, por consequência, no surgimento de novos comportamentos informacionais e comunicacionais.

Com a integração constante de conteúdos e as facilidades de acesso, a colaboração entre pessoas tornou-se cada vez mais comum através de fóruns, videoconferências, webinars e redes sociais, remetendo para o conceito de Sociedade em Rede (CASTELLS, 1999), na qual os nômades digitais pertencem. Por conseguinte, as pessoas devem ser coempreendedoras na pesquisa e partilha da informação, tendo a iniciativa, a decisão, a flexibilidade, adaptabilidade para trabalhar em equipe e solucionar problemas.

Não obstante, a interação e a colaboração online não estão presentes somente no meio laboral. Essa é igualmente uma realidade educacional, como mostra o artigo de Daniela Barros (2014), onde o foco está nas tecnologias utilizadas para a coaprendizagem e como elas proporcionam um "envolvimento dinâmico e participativo para a construção coletiva do conhecimento"(BARROS, 2014, p. 95).

O trabalho realizado em rede, tanto no âmbito profissional como no âmbito acadêmico apresenta um novo comportamento. A estrutura física (local) não é mais um fator imprescindível, contrariamente à tecnologia que faz parte do cotidiano dos cidadãos.

Em suma, a sociedade de informação está amplamente ligada às tecnologias e, por consequência, à "geração Google", aos nômades digitais e ao prefixo "co", ou seja, coaprendizagem e coempreendorismo, pois a ação humana deve ser norteada através da colaboração e partilha da informação entre todos. No entanto, para que isso aconteça é necessário que seus cidadãos tenham as competências digitais e multiliteracias necessárias, como veremos a seguir.

\section{Competências digitais}

As tecnologias exigem do utilizador, competências digitais cada vez mais avançadas. Dessa forma, produzindo e disseminando conteúdos em ambientes digitais abertos e partilhando o conhecimento para cooperação e a readaptação de assuntos. Ter competências digitais é essencial dado que a informação além de se ter tornado uma necessidade de sobrevivência (LANZI et al., 2012, p. 51), possibilita a construção de conhecimento, que por sua vez possibilita o progresso. Assim, ter informação de qualidade, segura e fidedigna é de extrema importância no processo de construção do conhecimento.

Souza, Okada \& Silva (2014, p. 135), introduzem o tema da literacia digital, afirmando que este vai muito além do acesso e do conteúdo, ela 
desenvolve práticas sociais em rede, ensinando os alunos a interagir com os outros e como agir socialmente online. Ademais, o uso da web permite uma miríade de comportamentos informacionais, como recolher, acessar, produzir, apresentar, trocar informação, comunicar e participar em redes colaborativas, contudo a literacia permite que estas ações sejam feitas de forma segura e crítica da mesma. Não obstante, Koltay apresenta o conceito de metaliteracia no seu artigo "Big data, big literacies?" (2014) que é exatamente o que Souza, Okada\& Silva defendem ser a literacia digital. Isto é, metaliteracia é a promoção do pensamento crítico e da colaboração na era digital, fornecendo uma estrutura abrangente para participar de mídias-sociais e comunidades online. Este tipo de literacia vai além das habilidades tradicionais de informação (determinar, acessar, localizar, compreender, produzir e usar informações), pois inclui a produção colaborativa e o compartilhamento de informações em ambientes digitais participativos (colaborar, produzir e compartilhar) predominantes nos dias de hoje.

Assim, literacia digital ou metaliteracia ganha um papel de destaque na educação da sociedade da informação. Contudo, esta mesma literacia não foi adquirida por todos ao mesmo tempo, dado que os "migrantes digitais" ${ }^{11}$ possuem diferentes necessidades informacionais para se adaptarem ao novo contexto tecnológico.

Vemos, assim, que as diferentes necessidades e consumo de informação afetam o comportamento dos cidadãos. Segundo Heinstöm (2005 apud HUVILAA; AHMAD, 2017, p. 2) existem três padrões de busca de informação: fast surfing, broad scanning e deep diving; e esses padrões podem ser divididos em três categorias: deep, surface estrategic. Fast surfing refere-se aos usuários que fazem uma busca rápida, sem precaução e pouco abertos a novas experiências; broad scanning, são utilizadores mais extrovertidos e competitivos, abertos às novas experiências; já os que utilizam deep diving, apesar de também serem abertos às novas experiências, o fazem de maneira mais analítica.

Portanto, os autores apontam que esses padrões não podem ser vistos isoladamente. O meio no qual o usuário está inserido, a necessidade e objetivos para a busca devem fazer parte da análise do comportamento informacional. Em sua pesquisa, Huvilaa e Ahmad (2017) apontam que o comportamento informacional se altera também, mediante a informação a qual o usuário tem acesso e que um comportamento informacional holístico atravessa contextos e que agrega valor no entendimento geral da situação e no autodesenvolvimento num âmbito profissional e individual.

\footnotetext{
${ }^{1}$ Cidadãos que nasceram antes da década de 1980 e tiveram que se adaptar aos novos meios tecnológicos e adquirir as competências digitais e informacionais.
} 
Elucidando o conceito de comportamento informacional, MartínezSilveira e Oddone (2007, p. 118) expõem que "todo comportamento humano relacionado às fontes e canais de informação, incluindo a busca ativa e passiva de informação e o uso da informação. Isso inclui a comunicação pessoal e presencial, assim como a recepção passiva de informação".

Mediante a este cenário de evolução tecnológica no qual competências digitais são necessárias para a construção de uma sociedade estruturada e inclusiva, a União Europeia lançou vários programas para formar cidadãos capazes digitalmente, como veremos a seguir.

\section{Políticas públicas}

A partir da Estratégia Europa 2020, que estabelece prioridades no crescimento inteligente, sustentável e inclusivo, mutuamente com a Agenda de Competências para a Europa (2016), foi definido um conjunto de ações com o objetivo de cooperação de todos os cidadãos, por intermédio de aquisição de competências digitais, tendo em vista a melhoria e aumento da empregabilidade e consequente competitividade dentro do espaço europeu (OCHÔA; PINTO, 2017, p. 387).

O referido envolvimento também se aplica às organizações, implicando dessa forma em uma nova estratégia referente ao capital humano. Dado que, para a correspondência com as políticas europeias é necessário que haja um maior envolvimento para combater o gap de competências digitais no centro de cada organização. À vista disso, para que uma organização seja sustentável, torna-se essencial equilibrar os desníveis existentes entre as capacidades da organização e as competências que permitem às organizações o cumprimento dos seus objetivos.

Tal como referido, com o avanço da tecnologia, a participação na cultura digital tem aumentado exponencialmente, permitindo o acesso livre a uma grande quantidade de informação e, ao mesmo tempo, de comunicação. Não obstante, nem todos os "migrantes"ou os "nativos digitais"têm o letramento necessário para acompanhar e interagir com a tecnologia e a informação digital, levando à exclusão digital ou ao não aproveitamento das capacidades tecnológicas.

Por isso, iniciativas como as que a União Europeia vem empreendendo no que concerne a literacia digital são importantes, não somente por seu papel de inclusão, mas pelos resultados que podem gerar, como por exemplo a emergência de novos campos de trabalho, em consequência, novos profissionais. Outra iniciativa que difunde a importância de ser digitalmente competente é a Ciência Cidadã, que promove 0 envolvimento de todos os cidadãos, podendo estes 
desempenhar vários papéis ativamente, como por exemplo criadores, gestores, curadores e consumidores de conhecimento.

Além disso, a Comissão Europeia desenvolveu um estudo, com base em um dos quadros de referência europeus, o Quadro Europeu de Competência Digital para Cidadãos chamado Digicomp (Digital competence framework for citizens) que oferece uma ferramenta para compreender e desenvolver as competências digitais dos cidadãos. Competênciasessas que são entendidas como: "conjunto de conhecimentos, atitudes e habilidades necessárias para se ter uma parte ativa nos ambientes digitais e colher os benefícios das tecnologias no quotidiano" (OCHÔA; PINTO, 2017, p. 393). Esse estudo identifica que a literacia de informação e de dados, comunicaçãa e colaboração, criação de conteúdo digital, segurança e resolução de problemas são áreas da competência digital.

Na linha das políticas europeias, foi desenvolvido em Portugal o Quadro Estratégico Plano Nacional de Leitura 2027 "que passa pela educação, pela cultura, pela ciência, tecnologia e ensino superior e pelas autarquias locais e que vê na literacia um instrumento indispensável de qualificação, inovação e competitividade do país para enfrentar os desafios deste século" (Quadro estratégico, 2017,p. 9). Por conseguinte, este Plano tem como objetivo melhorar as multiliteracias (literacia verbal, da informação, mediática, digital e outras) dos portugueses, com o intuito de diminuir o abandono escolar por parte dos jovens e melhorar as qualificações e competências da população, contribuindo para a inclusão dos cidadãos na sociedade de informação. O gestor e curador da informação é chamado, deste modo, a mediar e a exercer a sua ação colaborativa com a sociedade.

Neste mesmo propósito, o atual Presidente de Portugal, Marcelo Rebelo de Sousa, ao encerrar as programações do Web Summit 2018 evento anual sobre tecnologia, realizado nos últimos três anos em Lisboa (Portugal) - apela à consciência coletiva no que diz respeito ao uso das tecnologias, pois estas não devem andar distantes do que é social. Este último Web Summit marcou uma mudança no pensamento e na forma como as tecnologias e a internet são ou foram encaradas até então. Profissionais influentes na área, como Tim Berners-Lee e desenvolvedores de novos softwares alertaram sobre as implicações e as utilizações dos programas que desenvolvem. Questões como falta ética, segurança da informação e exclusão socio-digital foram abordados de forma veemente, visto que estes assuntos estão na ordem do dia, mas que até haviam sido abordados de forma superficial. Eles propuseram que esses temas sejam tratados apriori e não a posteriori, como vem acontecendo.

O gestor e curador da informação surge como uma das alternativas para solucionar esse problema, pois posiciona seu conhecimento logo na 
concepção de qualquer ideia de informação. Ademais, a Fundação WWW (World Wide Web Foundation) promove a literacia digital, um dos grandes aliados do gestor e curador da informação para a promoção das competências informacionais dos cidadãos, como previamente analisado nos pilares das competências digitais da Digicomp.

\section{Gestor e curador da informação}

Sabe-se que o ciberespaço conta com muitos dados desestruturados. Estes rastros digitais ficam permanentemente na internet e podem ser resgatados a qualquer momento. Porém, não há validação dessa massa informacional, qualquer produção pode ser publicada, lida, disseminada e interpretada de diversas formas.

Quanto ao aspecto colaborativo da criação de conteúdos, deve ser considerado a questão da avaliação desses processos. Conforme mencionado por Okada, Meister \& Barros (2013, p. 9) esse processo deve ser "aberto, colaborativo contínuo que integra teoria com prática num processo recursivo". Dado que os novos processos acontecem, e tendem a acontecer em rede, existe a necessidade de um mediador que entenda essas questões e tenha desenvolvido competências acadêmicas e profissionais que agreguem valor aos resultados obtidos. Neste ponto, observa-se que o papel do gestor e curador da informação é imprescindível.

O gestor e curador da informação nada mais é do que um coempreendedor, e que segundo Dolabela (2003, apudSOUZA; OKADA; SILVA, 2014, p. 136), é "alguém que sonha e procura transformar a realidade" [tradução nossa]. Portanto, a partir dos dados desestruturados, o gestor da informação transforma-os em informação com valor para a realidade atual e assim gera novo conhecimento.

O gestor e curador da informação possui a capacidade de análise, organização e gerenciamento. Com uma formação transdisciplinar e multidisciplinar, possui uma visão holística, associada ao avanço tecnológico que auxilia a gestão do conhecimento. Questões como análise de risco, pesquisa de mercado, data Science, marketing intelligence e business intelligence são algumas das questões analisadas por esse profissional, que utiliza a estruturação e organização dos dados para a tomada de decisões e criação do planejamento estratégico e assim ir ao encontro das novas tendências de comportamentos informacionais. O gestor e curador da informação auxilia a organização nas práticas de utilização da inteligência competitiva, que como esclarece Vidigal, Gonçalves \& Silva (2018, p. 209) "A prática da Inteligência Competitiva permite às organizações o desenvolvimento de uma cultura de busca por informações que, de forma efetiva, subsidiem as suas estratégias." 
É preciso trazer à visibilidade esta nova profissão que visa "Contribuir para a mudanças das formas tradicionais de gerir serviços de informação, identificando as tendências, oportunidades e impactos da atividade na sociedade, estabelecendo objetivos e metas de desempenho adequados [...]" (OCHÔA, 2014, p. 20).

Por conseguinte, cabe ao gestor e curador da informação estudar sistematicamente de que forma a literacia ou iliteracia informacional dos utilizadores se evidencia perante a procura da informação que necessitam através das situações e dos contextos em que se inserem. Segundo Armando Silva (2008, p. 36),

[...] as competências críticas na procura, na avaliação e no uso da informação dependem diretamente de condições do meio ambiente (político, jurídico-administrativo, económico, social, cultural de uma região, de um país ou de "espaço" civilizacional mais alargado), do contexto concreto em que se inscreve a(s) atividade(s) da pessoa e cada situação específica que, geralmente no interior de um contexto, desencadeia o motivo ou a necessidade informacional.

O papel do gestor e curador da informação se estabelece então como colaborador e mediador da informação. Colaborador, enquanto coprodutor de material informacional, e mediador, como um intermediário entre a informação e o usuário. Na Ciência da Informação, o termo mediação deve ser entendido como

"[...] toda ação de interferência - realizada em um processo, por um profissional da informação e na ambiência de equipamentos informacionais - direta ou indireta; consciente ou inconsciente; singular ou plural; individual ou coletiva; visando a apropriação de informação que satisfaça, parcialmente e de maneira momentânea, uma necessidade informacional, gerando conflitos e novas necessidades informacionais." (ALMEIDA JÚNIOR, 2015, apud, SANTOS NETO; ALMEIDA JÚNIOR, 2017, p. 257).

Segundo os autores, não existe mediação neutra, pelo contrário, ela é caracterizada como "colaborativa, participativa e potencialmente transformadora." (op.cit., 2017, p. 255). A ação de selecionar para se conservar, trabalho fundamental de um curador, é igualmente uma mediação, ainda que ela seja implícita. Essa mediação vem de encontro com as necessidades imediatas ou futuras do usuário. Cabe ao profissional identificar, conforme Barbosa e Almeida Júnior (2017, p. 58), "a verdadeira preocupação do leitor" para que possa gerir e buscar os materiais necessários consoante seu comportamento.

Diante do exposto, fica claro que o mundo se norteia pela informação. Ele a produz, a consome e a dissemina constantemente, 
mudando hábitos informacionais de acordo com a evolução tecnológica e está evoluindo de acordo com as novas necessidades informacionais. É um ciclo sem fim no qual o gestor e curador da informação se posiciona como um mediador e colaborador.

\section{Considerações Finais}

A partir do momento em que a Cultura foi constituída como um dos quatro pilares da sustentabilidade, a profissão de gestão e curadoria da informação passou a fazer todo o sentido na sociedade globalizada. No entanto, ela ainda não é visível para todos, principalmente para os principais interessados, os stakeholders.

Por conseguinte, esta profissão oferece às empresas, instituições ou organizações a possibilidade de estruturar os dados, analisá-los, avaliá-los e com isso criar valor à informação que dispõem para desenvolverem o marketing e a comunicação e assim criar impactos positivos nas partes interessadas. Ao mesmo tempo, esta profissão permite que se desenvolvam sistemas de informação, partilha e conservação de informação de forma sustentável e que se responda de forma eficaz às novas tendências de comportamentos informacionais.

Por fim, esta profissão será, sem dúvida, um fator de diferenciação e competitividade dentro de uma empresa, instituição ou organização. Pois são características do gestor e curador de informação a transdisciplinaridade e transversalidade de áreas, competências digitais e capacidade de literacia informacional, gestão e organizaçãodo ambiente digital, criatividade na criação de modalidades de serviço como marketing etc.

Diante do contexto de literacia e nomadismo digital, das novas relações de coaprendizagem, coempreendedorismo e através da análise das novas políticas europeias de competências digitais, este artigo demonstrou a importância do papel gestor e curador da informação nos novos comportamentos informacionais da sociedade da informação.

\section{Referências}

ALMEIDA JÚNIOR, Oswaldo Francisco de; SANTOS NETO, João Arlindo dos. Mediação da informação e a Organização do Conhecimento: interrelações. Informação \& Informação, [S.l.], v. 19, n. 2, p. 98-116, abr. 2014. ISSN 1981-8920. Disponível em:

http://www.uel.br/revistas/uel/index.php/informacao/article/view/16716/ pdf 25. Acesso em: 17 nov. 2018.

ALMEIDA Júnior, Oswaldo Francisco de; SANTOS NETO, João Arlindo dos. O caráter implícito da mediação da informação. Informação \& Informação: Estudos, João Pessoa, v.27, n.2, p. 253-263, maio/ago 2017. Disponível em: 
https://periodicos.ufpb.br/ojs2/index.php/ies/article/view/29249/18235. Acesso em: 10 nov. 2018.

BARBOZA, Elder Lopes; ALMEIDA JÚNIOR, Oswaldo Francisco de. A mediação da informação nas discussões sobre os fluxos informacionais. Informação em Pauta, Fortaleza,CE, v. 2, n. 2, jul./dez. 2017. Disponível em:

http://www.periodicos.ufc.br/informacaoempauta/article/view/30812/715 93. Acesso em: 10 nov. 2018.

BARROS, Daniela Melaré Vieira. Estilos de coaprendizagem e alguns indicadores das competências digitais. Educación, v. 23, n. 45, p. 91-105, 2014. Disponível em:

https://www.researchgate.net/publication/293593779 Estilos de coapren dizagem e alguns indicadores das competencias digitais. Acesso em:

30 out. 2018.

BURKE, Peter. Uma história social do conhecimento: de Gutemberg a Diderot. Rio de Janeiro: Jorge Zahar, 2003.

CASTELLS, Manuel. A Era da Informação: economia, sociedade e cultura. Lisboa: Fundação Calouste Gulbenkian, 2002. Vol. I e II.

CASTELLS, Manuel. Sociedade em Rede. São Paulo: Paz e Terra, 1999. Vol. I.

COMISSÃO EUROPEIA. Europa 2020: Estratégia para um crescimento inteligente, sustentável e inclusivo. Bruxelas: [S.n.], 2010. Disponível em: https://infoeuropa.eurocid.pt/registo/000043517/documento/0001/. Acesso em: 02 nov. 2018

GOUVEIA, Luis; GAIO, Sofia (orgs). Sociedade da Informação: balanço e implicações. Porto: EdiçõesUniversidade Fernando Pessoa, 2004.

HUVILA, Isto; AHMAD, Farhan. Holistic information behavior and the perceived success of work in organizations. Library \& Information Science Research, v. 40, n. 1, p. 18-29, 2018. Disponível em: https://www.sciencedirect.com/science/article/abs/pii/S07408188173006 71?via\%3Dihub. . Acesso em: 1 nov. 2018.

KOLTAY, Tibor. Big data, bigliteracies? Читалиште (Čitalište), v. 24, p. 38, 2014.

LANZI, Lucirene Andréa Catiniet al. Tecnologias de Informação e Comunicação no cotidiano dos adolescentes: enfoque no comportamento e nas competências informacionais da 'geração Google'. Informação \& Informação, [S.I.], v. 17, n. 3, p. 49-75, dez. 2012.Disponível em: 
http://www.uel.br/revistas/uel/index.php/informacao/article/view/11308. Acesso em: 30 oct. 2018.

MARTÍNEZ-SILVEIRA, Martha; ODDONE, Nanci. Necessidades e comportamento informacional: conceituação e modelos. Ciência da Informação, v. 36, n. 2, p. 118-127, 2007. Disponível em: http://www.scielo.br/scielo.php?script=sci arttext\&pid=S0100$19652007000200012 \&$ lng =pt\&tlng=pt. Acessoem: 11 nov. 2018

NASH, Caleece, et al., Digital nomads beyond the buzzword: Defining digital nomadic work and use of digital technologies. Lecture Notes in Computer Science, [S.I.], I Conference 2018, p. 1-10. Disponívelem: https://www.researchgate.net/publication/322923942 Digital nomads be yond the buzzword Defining digital nomadic work and use of digital $t$ echnologies. Acesso em: 19 out 2018.

OCHÔA, Paula. Empregabilidade e carreiras em InformaçãoDocumentação: novos ciclos de aprendizagem académica e ciclos de competências profissionais. In: ENCONTRO NACIONAL DE CENTROS DE DOCUMENTAÇÃO DE MUSEUS - DESAFIOS DA GESTÃO INTEGRADA DOS ACERVOS NOS MUSEUS, 3., 2014, Sacavém. Conferência. Sacavém: Câmara Municipal de Loures, 2014. p. 15 - 25. Disponível em: https://www.cm-loures.pt/media/pdf/PDF20171205151756081.pdf. Acesso em: 10 nov. 2018.

OCHÔA, Paula; PINTO, Leonor Gaspar. Transformação digital e competências digitais: estratégias de gestão e literacia. In: PEREIRA, Sara; PINTO, Manuel (Ed.). Literacia, Media e Cidadania - Livro de Atas do 4. ${ }^{\circ}$ Congresso. Braga: Cecs - Centro de Estudos de Comunicação e Sociedade, 2017. p. 386-398. Disponível em:

http://www.lasics.uminho.pt/ojs/index.php/cecs ebooks/article/view/268 9. Acesso em: 30 out. 2018.

OKADA, Alexandra; MEISTER, Izabel; BARROS, Daniela Melareira. Refletindo sobre avalia na era da co-aprendizagem e co-investiga. In: Livro de resumos da CATES 2013 - 1a Conferência internacional Avaliação e Tecnologias no Ensino Superior. [S.I.]: [S.n.]: 2013. p 1-23. Disponível em: http://oro.open.ac.uk/42571/. Acesso em: 30 out 2018.

OLIVEIRA, Arlindo. A Singularidade Tecnológica. O Público. Lisboa. 12 out. 2018. Disponível em:

https://www.publico.pt/2018/10/12/opiniao/opiniao/a-singularidadetecnologica-1847173. Acesso em: 12 out. 2018

QUADRO ESTRATÉGICO. Plano Nacional de Leitura 2027. Lisboa: [S.n.], 2017. Disponível em: http://pn|2027.gov.pt/np4EN/file/8/QE.pdf. Acesso em: 23 nov. 2018. 
SILVA, Armando Malheiro da. Inclusão Digital e Literacia Informacional em Ciência da Informação. Prisma.com, [S.I.], v. 7, p. 16-43, dez. 2008. Disponível em:

http://ojs.letras.up.pt/index.php/prismacom/article/view/2082/1917. Acesso em: 30 out 2018.

SOUZA, Karine Pinheiro de; OKADA, Alexandra; SILVA, Bento.

Competences for co-entrepreneurship: contribution to the understanding of the concept for Entrepreneurial education. International Congress on Education, Innovation and Learning Technologies Barcelona: [S.n.], 2014. p. $134-146$

VALENTE, Liliana. Marcelo exorta portugueses a "despertarem" e "agirem" contra populismos. O Público. Lisboa, p. 00-00. 09 nov. 2018. Disponível em: https://www.publico.pt/2018/11/09/politica/noticia/marcelo-exortaportugueses-despertarem-agirem-populismos-1850461. Acesso em: 09 nov. 2018.

VIDIGAL, Frederico; GONÇALVES, Carlos Alberto; SILVA, Joaquim Ramos. Inteligência competitiva e capacidade de inovação: uma análise de uma indústria de classe mundial no setor automotivo de veículos pesados. Perspectivas em Ciência da Informação, [S.I.], v. 23, n. 3, p. 206-220, set. 2018. Disponível em:

http://portaldeperiodicos.eci.ufmg.br/index.php/pci/article/view/317. Acesso em: 08 dez. 2018.

VIEIRA VITORIANO, Maria Albeti; GASQUE, Kelley Cristine Gonçalves Dias.Comportamento de pesquisa e uso de informações irrelevantes no ambiente de trabalho. Encontros Bibli: revista eletrônica de biblioteconomia e ciência da informação, Florianópolis, v. 23, n. 53, p. 7886, set. 2018. ISSN 1518-2924. Disponível em: https://periodicos.ufsc.br/index.php/eb/article/view/15182924.2018v23n53p78. Acessoem: 23 nov. 2018. 